\title{
チタン基硬質焼結材料の開発
}

徳本 啓, 北田 哲則

東明 広宜, 坂口 茂也

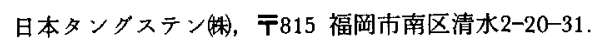

\section{Development of a Sintered Titanium Base Hard Alloy}

Kei Tokumoto, Tetsunori Kitada

Hironobu Shinoaki and Shigeya Sakaguchi

Nippon Tungsten Co., Ltd., 20-31 Shimizu 2-Chome Minami-ku, Fukuoka 815.

Received September 3, 1992

\begin{abstract}
Ti-Mo-(33 80)mass\%TiC alloys were prepared through P/M technology and their microstructures and mechanical properties were investigated. These alloys were revealed to have two phases, those were $\mathrm{TiC}_{\mathbf{x}}$ phase and $\beta$-Ti phase. The lattice constant of TiCx was increased with increasing $\mathrm{TiC}$ content, associating with increase of $x$. On the other hand, increase of TiC content decreased the lattice constant of $\beta$-Ti due to increase of Mo content in $\beta-\mathrm{Ti}$. Furthermore, increase of TiC content increased hardness of the alloys but slightly decreased transverse-rupture strength. It was concluded that $\mathrm{Ti}$ Mo-45mass\%TiC alloy had better combination of hardness and transverse-rupture strength than that of conventional Ti-Mo-33mass\%TiC alloy.
\end{abstract}

\section{1 緒 言}

チタン合金は優れた耐食性を有し，化学工業，航空 機工業などで使われている.なかでも，モリブデンを 含むTi-(15-30)\%MO合金は, 純チタンよりはるかに優れ た耐食性を有する”。しかし，この合金には，通常の 溶製法では重力偏析が生じる，機械加工性が悪いなど の問題点があった2! .これを解決するために，粉末治

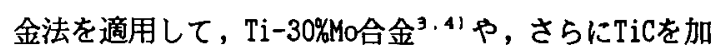
えて耐摩耗性を向上させたTi-Mo-33\%TiC合金5)などが 開発され，実用化されている.

しかし，これら合金の組織は，まだ明確ではない。 またTiCを含む合金は, 而摩耗性が良いとはいいながら
もHv550(HrC55)程度の硬さであり，超硬合金やセラミ ックスなどに比べると十分とはいえない。

そこで,ます組織をTiC添加量との関係で検討し，さ らにTiC量を増やすことにより硬さの向上を試みた。

\section{2 試料調製および実験方法}

市販のTi，Mo,TiC粉末を用い, 所定量に配合後, らい 潰機にて3.6ks混合し，200MPaにてブレス成形した。こ れを1673k〜1873Kにて7.2ks真空焼結した。ここで， TiC量は33mass\%〜80mass\%まで変化させ, 残りのTi,Mo の比が筫量で7:3一定となるようにした．

得られた焼結体について收縮率, 密度を測定し,さ 
らに, SBM組織観察, EDXによる組成の定量分析 (Ti$30,50,70 \%$ Mo合金を標準試料として定量），X線回折な どにより組織を明らかにしようとした.なお，一部の 合金についてはC,0分析 (それぞれ塐堀場製作所製カー ボン分析機BMIA-2110, LECO社製酸素窒素分析機TC36を 使用）も実施した.

さらに, 平面研削後, 硬さ, 抗折力 $\left(\right.$ 断面 $4 * 8 \mathrm{~mm}^{2}$, スパン $20 \mathrm{~mm}, 3$ 点曲げ) などを調查し,これらの値が高 くなる組成を検討した。

\section{3 実験結果および考察}

Fig.1には相対密度に及ぼす焼結温度とTiC量との影 響を示す.いずれの合金でも焼結温度が高いほど相対 密度は高くなり, いずれの狫結温度でもTiC量が多いほ ど相対密度は小さくなる. 特に, TiC 量が60\%以上では 相対密度は95\%以下であり, 焼結性に劣る.これは難 焼結性のTiC量が増えるので当然であろう.

Photo.1には1773Kで焼結した各合金のSEM組織を示す. いずれの合金も黒灰色領域, 灰白色領域およびポアか ら成る. ただし80\%TiC合金には灰白色領域はない. TiC量が増加すると共に黒灰色領域が増加するので, これはTiC相と思われ, 一方, 灰白色領域は $\beta-\mathrm{Ti}^{2}$ 相 ${ }^{6}$ (体心立方晶) と思われた.これは後述するX線回折で 確認された. なお, $80 \% \mathrm{TiC}$ 合金では $\beta$-Ti相は認められ ないので,この合金中では $\beta-T i$ TiC中に全て固溶し たものと思われる（後述）。ここで, TiC相粒内はほぼ 均一であり, $\mathrm{TiC}-\mathrm{Mo}_{2} \mathrm{C}-\mathrm{Ni}$ 系サーメットで生じるTiC相 粒の有芯構造, いわゆる周辺組織》1 は認められなかっ た.これについては今後検討したい.

ポアはTiC量の増加と共 に粗大化し, かつ量も増 えている.これはFig.1の 結果に対応する. 次にSEM 組織に及ぼす焼結温度の 影響を33TiC\%，45\%TiC合 金を例にPhoto.2に示す. いずれの合金も焼結温度 が高くなるとTiC相, $\beta$ Ti相のいずれも粒成長す る.またポア量は焼結温
度が高いほど減少している.なお, 合金中のTiC相量は 焼結温度が高い方がやや多く見える．これらの傾向は、 TiC量の異なる合金でも同样であった。

そこで， Fig.2には合金中のTiC相量を組織写真から 測定した結果を焼結温度，TiC量との関係で示す．図に は配合時のTiCの体積\%も併示した. 合金中のTiC相量 は, いずれの合金も焼結温度が高い方が増加する傾向 にある. また当然ながら合金中のTiC相量は配合した TiC量と共に増加するが, その量は配合時よりも増えて いる. 特にTiC配合量が少ない時に増え方が大きく, 配 合TiCが33mass\%(35.1vol\%)に対して合金中TiCが55〜

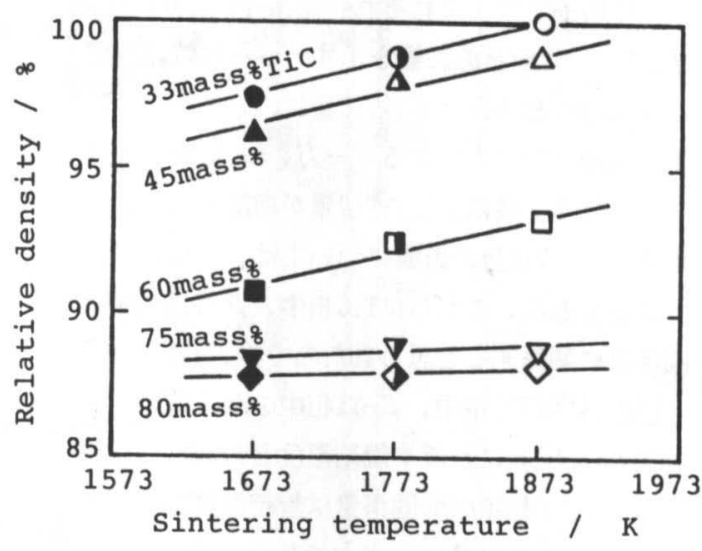

Fig.1 Relative densities as a function of sintering temperature and TiC content.

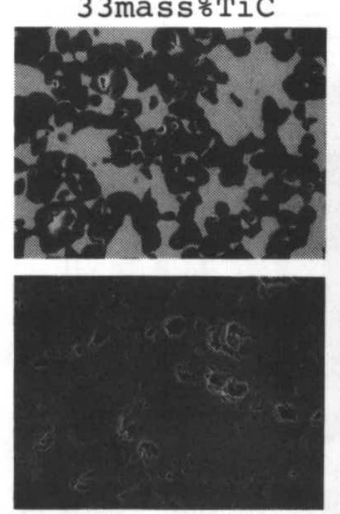

$75 \mathrm{mass} \% \mathrm{TiC}$

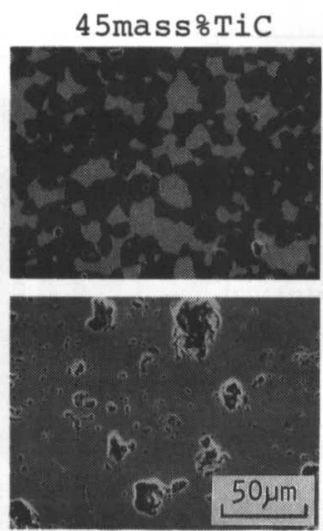

$80 \mathrm{mass} \% \mathrm{TiC}$

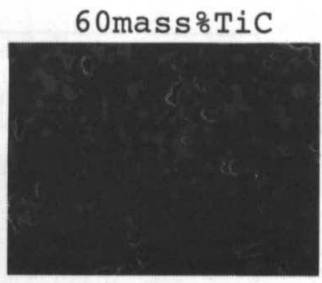

Photo.1 SBM microstructures of Ti-Mo-(33 80)mass\%TiC alloys sintered at $1773 \mathrm{~K}$ for $7.2 \mathrm{ks}$. 
62vol\%と約 2 倍にもなることが注目される.この 事実は, TiC相, $\beta$-Ti相のいずれにも, 配合時に 比べ大幅な組成変化があったことを示唆する．

Pig.3には1773K燒結の33\%TiC合金のX線回折例を 示す. 図中にはTiC相と $\beta-T i$ 相のピークのみが認 められるので, 33\%TiC合金はこれらの2 相合金で ある.これは焼結温度に依らず同様であった．ま た，他の合金も同様に 2 相合金であった．ただし 80\%TiC合金では $\beta$-Ti相のピークは認められなかっ た、結果は略したが, それぞれのピーク位置は， TiC量, 焼結温度に依存した。

そこで, Fig.4(a)にはTiC相, Fig.4(b)には $\beta$ $\mathrm{Ti}$ 相の格子定数 (それぞれ的 $\mathrm{T}_{\mathrm{c}}, \mathrm{a}_{\mathrm{T} 1}$ ) に及ぼす焼 結温度とTiC量との影響を示す。 $a_{\mathrm{Ti}} \mathrm{c}$ は焙結温度 にはほとんど依存せず, TiC量にのみ依存し, TiC 量の増加と共に大になる。一方, $a_{\mathrm{T}}$ は燒結温度 が高くなると共に, またTiC量が增加すると共に

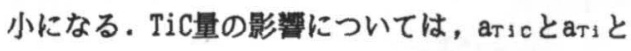
では逆である。これらはTiC相中， $\beta$-Ti相中のMo 固溶量に関係すると思われたので検討した.

Pig.5にはTiC相中, $\beta-\mathrm{Ti}$ 相中のMo固溶量 (そ れぞれ(a,b))に及ぼす焼結温度とTiC量との影響 を示す. TiC相中のMo固溶量は燒結温度が高いほ ど，またTiC量が多いほど大である，ただし，固 溶量は最大でも約4mol\%であり，多くはない， $\beta$ $\mathrm{Ti}$ 相中のMo固溶量は, 同様に焼結温度が高いほど, またTiC量が多いほど大である.しかもその量は $25 \mathrm{~mol} \%$ か $585 \mathrm{~mol} \%$ と大きく変化する.配合した時 点では17.6mol\%Moなので, かなり増加することが 分かる.
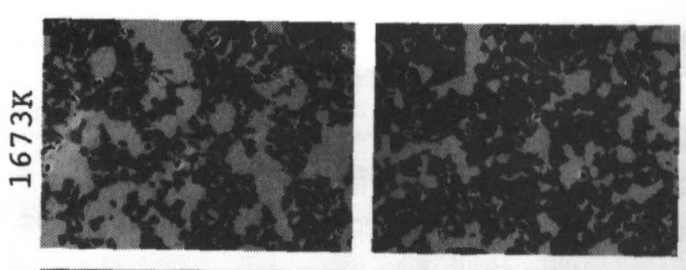

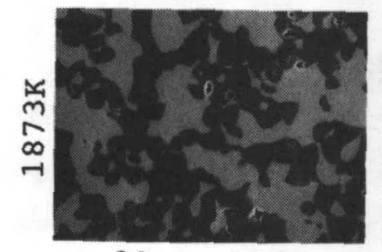

33 mass $8 \mathrm{TiC}$

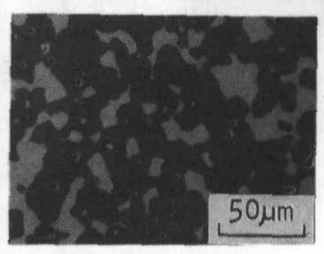

45 mass 8 TiC
Photo.2 SEM microstructures of 33\%TiC and $45 \%$ TiC alloys sintered at $1673 \mathrm{~K}$ and $1873 \mathrm{~K}$.

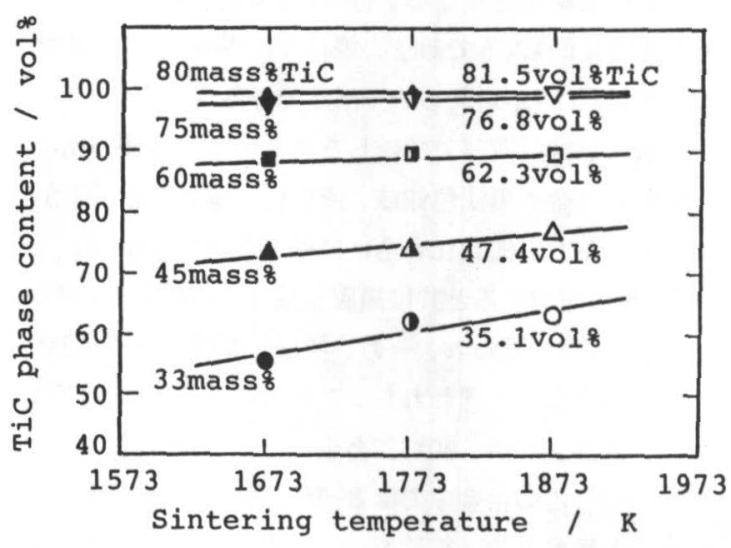

Fig.2 TiC phase contents as a function of sintering temperature and TiC content, which is shown in the figure.

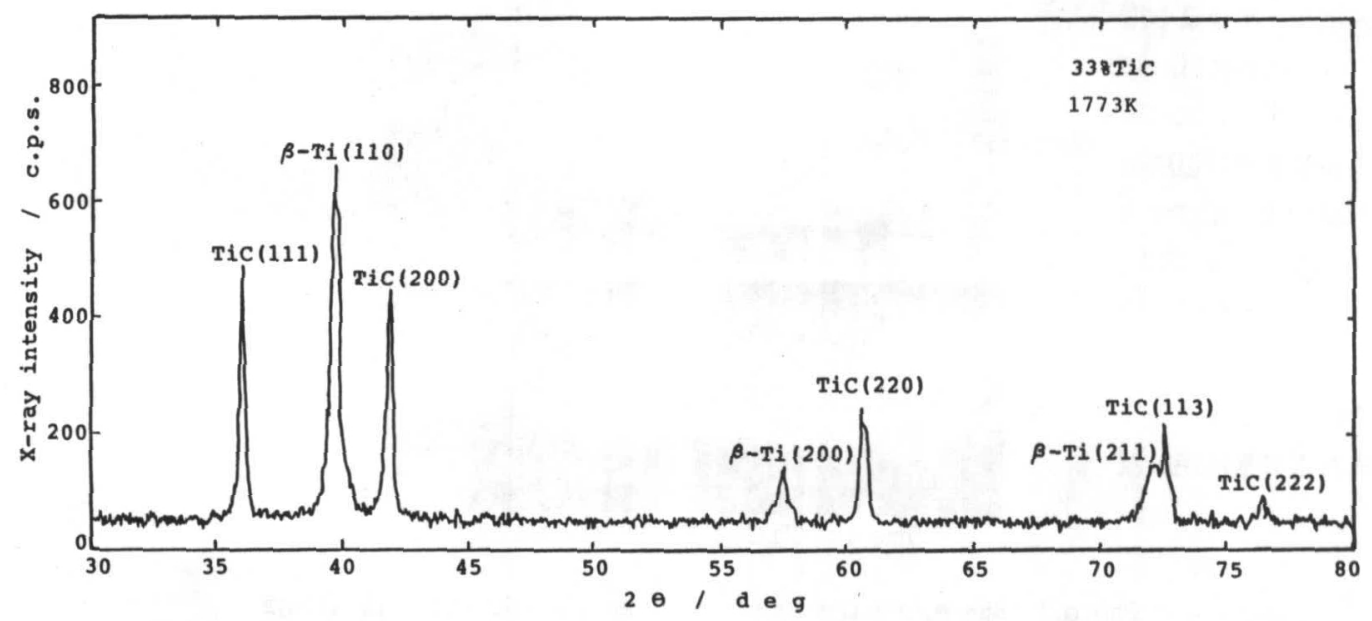

Fig.3 An example of a X-ray diffraction pattern of $33 \%$ TiC alloy sintered at $1773 \mathrm{~K}$. 
後者の $\boldsymbol{B}$-Ti相から述べる. 原子半径はTiの方がMoよ りも大 (それそれ $0.147 \mathrm{~nm}, 0.136 \mathrm{~nm}^{81}$ ) なので, Moの 固溶量が増すと $\mathrm{a}_{\mathrm{Ti}}$ は減少する”ことが知られている。 既述のように， $\beta$-Ti相中のMo固溶量は，焼結温度が高 いほど, またTiC量が多いほど大であるが，その時的い は小であった。したがってатが小になるのはM固溶量 が大になるためとして良い。

一方，aTıcはM固溶量が大（この時TiC量も大）にな る時に大になっており, 上述の結果とは逆で理解でき ない.ところで, TiCxは非化学量論組成の化合物であ

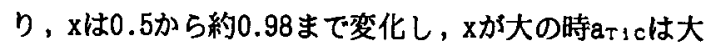
になる ${ }^{(0)}$. そこでTiC中のC量を見櫴もることとした。 まず1773K焼結合金であるか，C量は33\%TiCから80\%TiC までTiC量と共に増加し，それぞれ6.32mass\%，8.52\%， $11.51 \% ， 14.21 \% ， 15.20 \%$ あった。これは容易にmol量 に換算できる。またig.2のデータからTiC相のmol量も 算出でき，これらから社計算すると，それぞれ0.50， $0.55,0.62,0.71,0.75$ が得られた.すなわち, TiC量 が多いほどxが大になることが示された。 そうすると， Fig.4(a)のようにTiC量が多いほどaTıが大になったの は，奴大になったためとして理解された。なお，燒結

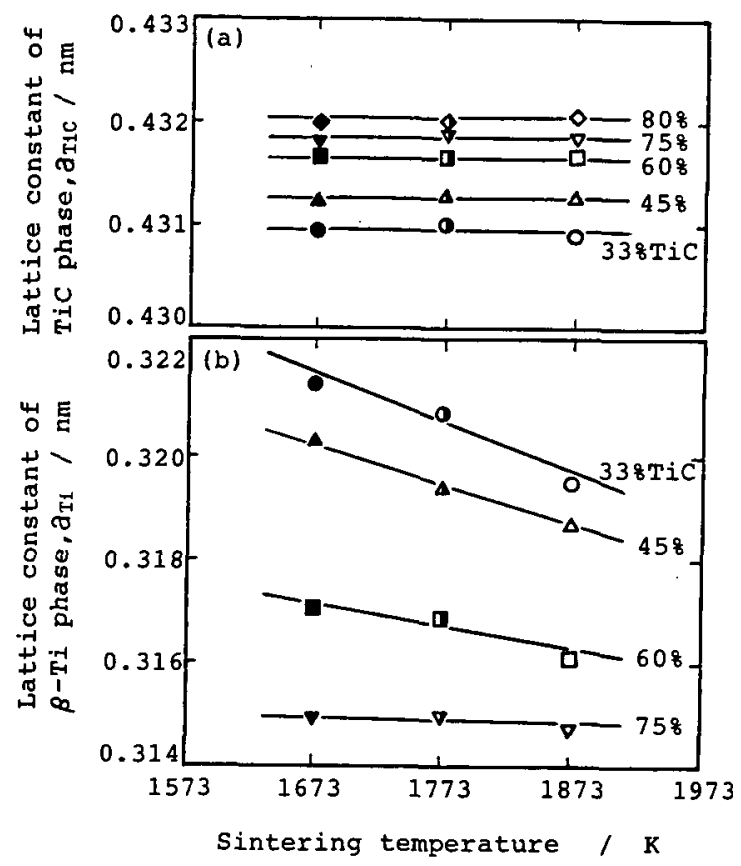

Fig.4 Lattice constants of TiC phase ( $a, a_{\mathrm{Tr}} \mathrm{c}$ ) and $\beta$-Ti phase $\left(b, a_{T s}\right)$ as a function of sintering temperature and $\mathrm{TiC}$ content.
温度による影響は省略したが，同様にして理解できた。

以上から明らかになった相関係を, RudyのTi-Mo-C 3 元系等温断面図" した．傾向はRudyの状態図に一致している，一方， (Ti,Mo)C固溶体である $\delta$ 領域がカーボンpoor側に広が っていること, 共役線の傾きがTiリッチ隅で異なるこ

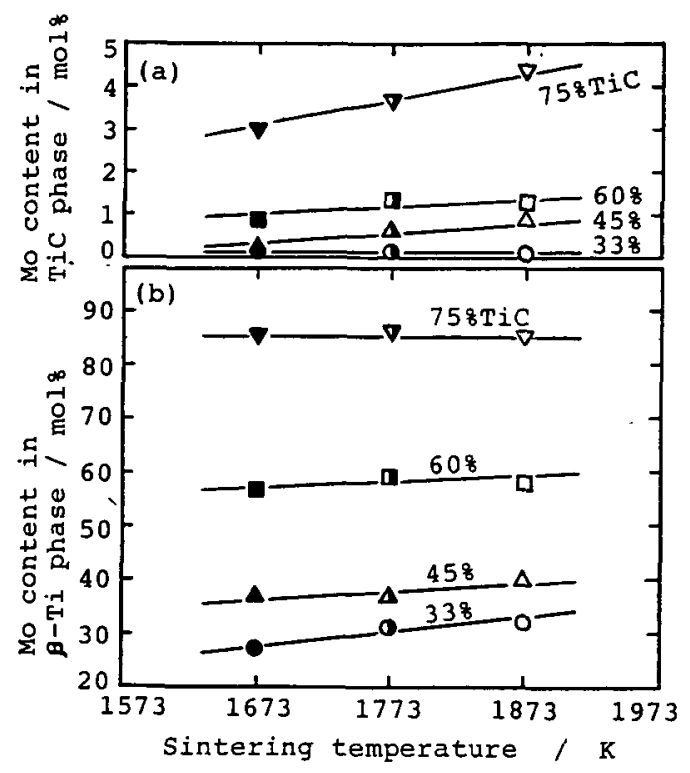

Fig. 5 Mo contents in TiC phase (a) and $\beta$ - $\mathrm{Ti}$ phase (b) as a function of sintering temperature and $\mathrm{TiC}$ content.

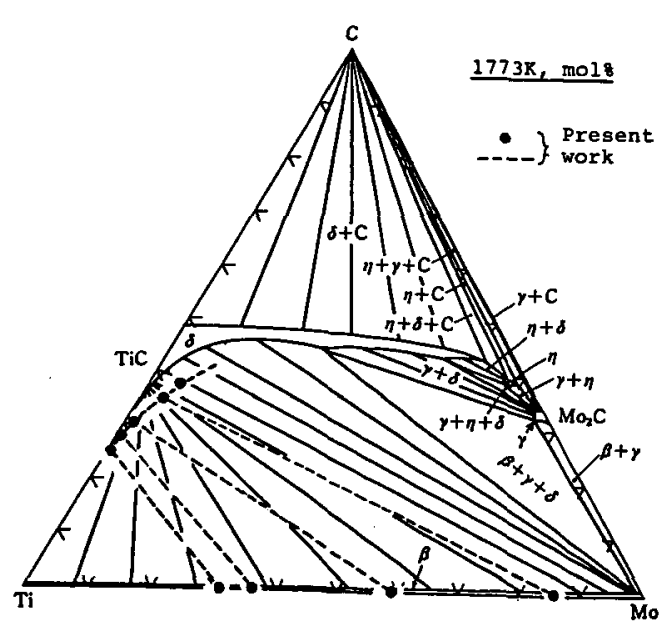

Fig.6 Rudy's Phase diagram of Ti-Mo-C. Present works were also plotted. 
との 2 点が相違している，なお前者についてはTiC $。$ 最小の於0.5である(0)とする結果には一致している。

上記 2 点の相違の理由はここでは明確ではないか， 本研究では焼結をしただけであるので，十分に平衡に 達していないことも関係しよう.なお酸索は最大 $0.7 \%$ 検出されたが，これも関係する可能性がある。これら の詳細については，今後の検討が必要である.ともか くも焼結する実用上，十分な相関係図が得られた．

以上で組織が明らかになったので，次に，機械的性 貿を検討した． Fig.7に硬さ(a)，抗折力(b)に及ぼす焼 結温度とTiC量の影翌を示す、燒結温度が高くなると， 33\%TiC添加では, 硬さが大になるが, 45\%添加以上では, おおよそ1773Kまでは硬さが大になり，それ以上では小 になった。またTiC添加量が大になるほど硬さが大にな るが，45\%㬄加以上ではこの傾向は飽和した.そして最 高でHRC66に達した。これは実用化されていた33\%TiC合 金より $\mathrm{H}_{\mathrm{R}} \mathrm{C} て ゙$ 約10（Hvで約250）も高硬度である.

一方, 抗折力は焼結温度が高いほどまたTiC添加量が 大になるほど小になった。ただし，実用化されていた 33\%TiC合金は約0.6GPaであり，TiCを増した45\%TiC合金

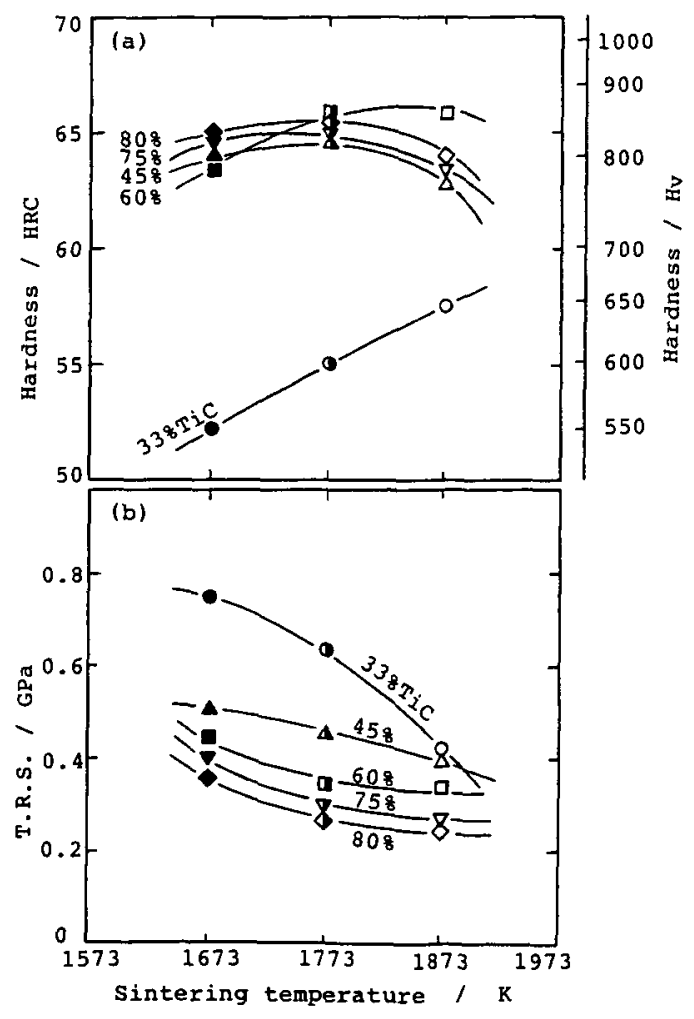

Fig.7 Hardness (a) and transverse-rupture strength (T.R.S.) (b) as a function of sintering temperature and TiC content.
では約0.45GPaであるので，使用可能な值である．以上 の硬さと抗折力からすれば，45\%TiC合金が優れると思 われた。

さて，これらの硬さと抗折力は，組織因子，すなわ ち合金中TiC相量, TiC粒径, 各相の組成，ポアなどに 支配されると考えられる，そこでまずは，合金中TiC 相量で，硬さ，抗折力を整理し，Fig.8(a,b)に示した. 図中には焼結温度も併示した。

硬さは，合金中TiC相量と共に增加するが，TiC相量 が75vol\%（添加TiC量 45mass\%）以上では飽和する．前 者は，硬筫相が增えるので当然である，後者は，硬質 相が増え硬さが增加する効果と，ポアが増え硬さが減 少する効果とが相殺したためと考元られる。結果は略 すが, TiC粒径, 各相の組成の影響は明確にできなかっ た・たたし，TiCを微粒化できれは，当然硬さは向上す ると考えられる．それ故，硬さをさらに问上させるに はHIP処理などでポアを減少させること，およびTiCの 徽粒化などが必要である。これらについては，今後検 討したい。

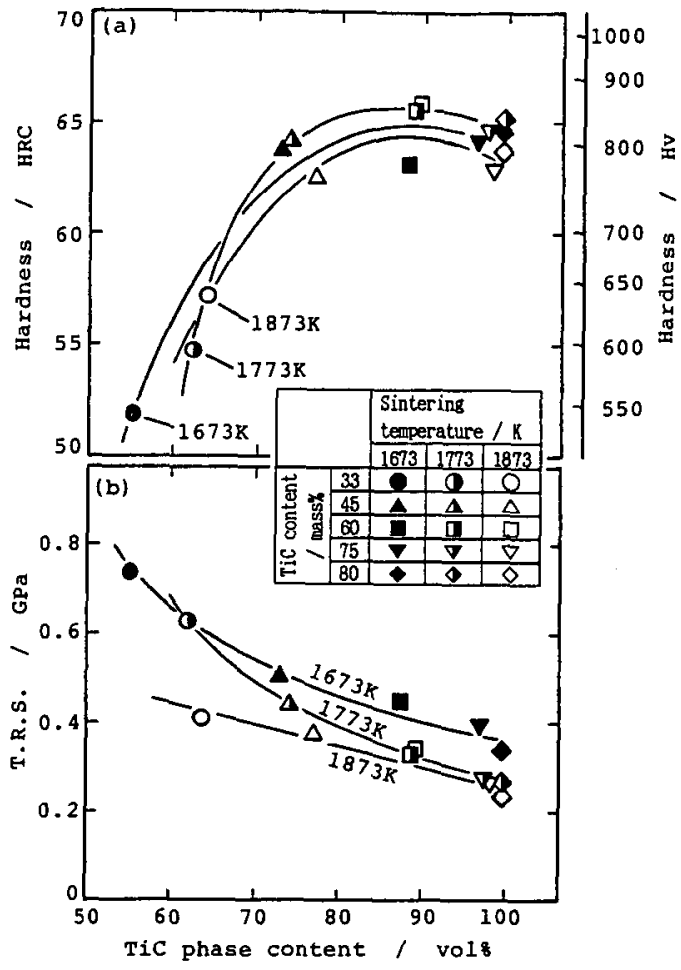

Fig.8 Hardness (a) and transverse-rupture strength (T.R.S.) (b) as a function of $\mathrm{TiC}$ phase content and sintering temperature. 
抗折力は合金中のTiC相量が大になるほど，また焼結 温度が高いほど小になった．前者の結果は，TiC相量の 増加にともないポア童が増加すること，および金属相 である $\boldsymbol{\beta}$-Ti相が娍少し，脆いTiC相同士が直接接する ようになるためであろう（Photo.1参照）．後者の結果 は，焼結温度が高いほどTiC相が粒成長するためと思わ れた。なお, 各相の組成変化も関係すると思われるが, ここでは明確にならなかった．上述の結果から，抗折 力をさらに向上させるには, HIP処理などでポアを減少 させること，およひTiCの微粒化などが必要と思われた。 これらは今後検討が必要である.

以上より，Ti-Mo-TiC合金の組織が明らかになり，ま た従来実用化されていたTi-Mo-33\%TiC合金よりも高硬 度で, 強度も十分なTi-Mo-45\%TiC合金が得られた。酎 食性も当然優れると考えられるので, 関係用途への応 用が期待される。

\section{4 総 括}

Ti-Mo-(33\%〜80\%)TiC合金を粉末治金法で調製し，組 織と機械的性質を検討し，高硬度の合金を得ようとし た.そして以下の諸結果を得た.

(1)組織はTiC相， $\beta-T i$ (体心立方晶) 相の 2 相であり， TiC相量は，配合時より，1.2〜2倍に增える.

(2) TiC相の格子定数は焼結温度には依存しないが, $\mathrm{TiC}$ 量の増加と共に大になる.一方， $\beta$-Ti相の格子定 数は焼結温度が高くなると共に，またTiC量が增加 すると共に小になる.前者は, 非科学量論組成の化 合物であるTiC のXが0.5から0.75へと增加するため に生じ，後者は $\beta-T i$ 相中のMo固溶量が $25 \mathrm{~mol}$ \%から $85 \mathrm{~mol} \%$ と著しく增加するために生じる．

(3)得られた相関係を, RudyのTi-Mo-C 3 元系等温断面 図と比較した結果，傾向はRudyの状態図に一致する が, (Ti,Mo)C固溶体である $\delta$ 領域がカーボンpoor側
に広がること，共役線の㑯きがTリリッチ隅で異なる ことなどが分かった．詳細は検討が必要である．

（4）硬さは，合金中のTiC相量と共に増加するか，TiC相 量が75vol\%以上では飽和し, 最大HRC66に達した。

(5)抗折力は合金中のTiC相量が多いほど, 焼結温度が 高いほど小であった。

（6)45\%TiC合金は，硬さ約 $\mathrm{H}_{\mathrm{R}} \mathrm{C} 64$ ，抗折力約0.45GPaと， 高硬度の割に高い抗折力を有する．これは㬰用化さ れていたTi-Mo-33\%TiC合金よりも高硬度で, 強度も 十分であり，耐摩耗酎食用途への底用が期待される.

\section{文 献}

1)B.Gelas, J.L.Crolet, L.Seraphin, R.Tricot \& R.Castro:Revue de Metallurgic Janvier(1973)1.

2)G.I.Friedman: Int.J.Powder Met., 6(1984)14.

3)伊藤 普，三橋 靖郎，田口 幸二 : 粉体および粉末 冶金 21(1975)248.

4)坂口 茂也:粉体および粉末冶金, 35(1988)58.

5)伊藤 普, 三橋 靖郎, 田口 幸二 : 粉体および粉末 诒金 $22(1975) 115$.

6)M.Hansen \& K.Anderko: "Constitution of Binary Alloys", MCGRAW-HILL, N.Y., (1958)976.

7)鈴木 寿, 林 宏爾, 寺田 修: 日本金属学会誌, 35(1971)936.

8)日本金属学会編, "改訂 2版 金属データブック", 丸善, (1983)496.

9)W.B.Pearson: "A Handbook of Lattice Spacings and Structures of Metals and Alloys", Pergamon Press, Oxford, (1958)876.

10)Storms: "The Refractory Carbides", Academic Press, (1976) $3 \& 8$.

11)E.Rudy: "Compendium of Phase Diagram Data, AFML-TR-65-2 Part V" Wright Patterson, (1969). 